\title{
4 The spatial dimension of mobility poverty
}

\author{
Tobias Kuttler
}

\begin{abstract}
Mobility poverty is intrinsically linked to spatial dynamics. Geographies and spatial systems influence how people move. Conversely, movements of all kinds have an impact on locations. They shape the built environment by adding to it the necessary infrastructure for mobility. Mobilities also co-create spatial typologies with particular mobility-related characteristics, such as car-dependent suburban neighbourhoods. Similarly, experiences of mobility disadvantage may be shaped by spatial disadvantages, e.g. by peripheral location in the spatial system. However, the relationship between mobility poverty, spatial factors and social exclusion is never a determinism or automatism, as will be shown. Therefore, this chapter will first provide an overview of spatial systems and dynamics in Europe before turning towards specific challenges in the urban and rural context.
\end{abstract}

\section{Mobility and the spatial system of Europe}

As outlined in the introduction to this volume, the study of unequal mobilities is closely linked to understanding uneven spatial development. Therefore, it is important to understand how these mobilities and geographies interact, with the aim of identifying and analysing the spatial specificities and characteristics of mobility poverty, taking into consideration the geographic elements of dwelling and moving.

The spatial conditions of mobility are determined by several factors. Density, location in the rural-urban network and accessibility are the spatial factors that have a strong impact on individual mobility behaviour and needs as well as the ability to move (motility). Hence, an analysis of the spatial conditions of mobility poverty needs to consider spatial dynamics in Europe. Urban expansion, suburbanisation and reconfiguration of the European spatial system have resulted in an urban-rural transition zone, referred to here as the peri-urban areas. These areas are very dynamic and are themselves in a process of constant transformation, posing taxonomic problems in their definition. They exhibit demographic, socio-economic and 
other characteristics that are different from purely rural and urban areas, with specific impacts on individual mobilities and mobility systems. Indeed, suburbanisation and peri-urbanisation (as well as the parallel processes of re-urbanisation) pose a substantial challenge to defining what is urban and what is rural today. Cities in Europe and all over the world have grown beyond their former city limits, a circumstance that makes it necessary to fully understand the implications of definitions such as "rural", "urban" and "peri-urban".

Keeping in mind the challenge of definitions among geographical arrangements, it is true that geography and mobility are linked to each other in myriad and complex ways. The spatial distribution of human activities, movement of people and goods between places and spatial characteristics interact with and inform each other. They form a system that is under constant transformation. Far from being direct causal relationships and determinants, the relationship between geography and mobility is often subtle and therefore often not clearly understood. Too often, development projects - seemingly well executed and based on the principles of integrated planning - have failed, challenging some of the fundamental assumptions about the interaction between space and mobility.

Density is one of the concepts that are often employed when trying to understand the relationship between space and mobility (Frey and Zimmer 2000). In the past, the density of human activities in a certain location certainly shaped evolution and the basic conditions of how people travel on an everyday basis. Conversely, the conditions of transport systems have influenced locational choices. A high density of people, activities and opportunities justifies sophisticated transportation infrastructure and networks as well as a high frequency and speed of transport services. High capacity transport systems are a prerequisite for maintaining and fostering the competitiveness of an economic location. Accessibility is thus most advanced in regions with a high density of population and economic activity.

When living and working was still located in the same place or close to each other, the need for more elaborated modes of transport was not universal. The limits of walking distance shaped early towns and settlements in Europe with their characteristic densities and associated benefits, but also had negative ramifications. With sustainability having become the primary guiding principle for spatial development, reference to Europe's spatial history is often made when envisioning the ideal city in terms of size and density. With the renaissance of non-motorised mobility in cities across Europe, dense and compact urban development is once again one of the primary objectives in spatial planning. A compact urban structure combined with a spatial system that is characterised by a hierarchical structure of equally developed main urban hubs with regional centres and smaller settlements is conducive to the use of public and non-motorised transportation. 
This chapter will start with the most important spatial dynamics in the more recent history of Europe, i.e. suburbanisation and peri-urbanisation. As mentioned above, changing locations of living, work, leisure, etc. and the way they are separated from each other - or concentrated in one place substantially influence everyday mobility. It will be shown that local, regional as well as global factors have an impact on the intertwined processes of urban expansion and concentration. After having outlined these spatial dynamics in Europe, a better understanding of spatial definitions and categories will be provided. Next, we employ a European macro perspective to illustrate the issue of accessibility to vital urban functions before closing this chapter with a short discussion on commuting.

\section{Suburbanisation and peri-urbanisation in Europe}

Residential suburbanisation in Europe has resulted in a separation of workplaces and places of living with larger distances being travelled on an everyday basis. However, the fact that the historic core cities remained major centres of employment, supply and culture means that a substantial part of personal travel is still directed towards the urban centres, supporting public transport use along main corridors. Unlike Europe, other parts of the world have seen a much more dispersed spatial pattern of suburbanisation that was - and still is - overwhelmingly car-based. Furthermore, in many places, residential suburbanisation was followed by suburbanisation of work, leisure and shopping (Hall 2003; Hart 2000).

The characteristic result of suburbanisation in Europe is a circle of wealthy rural communities around a core city, characterised by urban professionals living there and commuting to the urban core (Nelson and Sanchez 1999, 689). Apart from urban professionals, industries and services have been relocating to rural areas, especially in the second half of the 19th century, when there was a strong tendency towards urban deconcentration and counter-urbanisation (Ravetz, Fertner and Nielsen 2013, 17). Ex-urban retirement settlements are another form of suburb that can be found for example in Spain (Zasada et al. 2010), also second and holiday homes.

However, suburbanisation is only one of the processes that caused urban expansion and differentiation of Europe's historic spatial system: there has been an outward process from the city to the fringe, what is usually understood as suburbanisation. While the relocated households, commerce, industries, services and entertainment usually remain in close functional connection with the core city, more recently a variety of spatial uses has been established outside core cities. These types of uses may be in spatial proximity to a certain city, but are functionally more closely linked to global networks, such as industrial production chains. Such diverse and often contradictory spatial processes are subsumed under the 
term "peri-urbanisation" in contemporary literature. This term describes spatial development taking place in "transition zones" that are considered "something in between", neither fully urban nor rural (Allen 2010; Ravetz, Fertner and Nielsen 2013).

Peri-urban regions are the most dynamic regions of urbanised Europe and they exhibit a range of - sometimes conflicting - transport-related characteristics and mobility requirements. Still, there is much confusion about the geographical extent of the peri-urban: often, the peri-urban is known as the peri-urban fringe (e.g. Errington 1994). Peri-urbanisation is used in combination with other terms like urban sprawl, suburbanisation, ex-urbanisation and re-urbanisation (Gant, Robinson, and Fazal 2011); also, in different academic traditions, different terms are used to describe similar processes, for example in Germany and France (Forum Mobile Lives 2013).

That being said, authors generally agree anyway that the peri-urban, or the urban fringe, is the zone between the urban and the rural that is under transformation (e.g. Council of Europe 2007; Douglas 2012; Zasada et al. 2011). The term peri-urban thus describes less a specific territory, but rather a process of incremental and "incomplete" urbanisation. Ravetz, Fertner and Nielsen $(2013,13)$ have highlighted that the peri-urban can be seen not just as a zone of transition, but rather "a new kind of multi-functional territory".

However, when peri-urbanisation is understood as a process, the challenge remains how to define the peri-urban geographically. Ravetz, Fertner and Nielsen (2013) have suggested the term "rural-urban region" and an associated comprehensive methodology to define the peri-urban geographically, based on an extensive literature review. They identify two spatial types (Ravetz, Fertner and Nielsen 2013, 18-19):

1 Urban fringe: a zone along the edges of the built-up areas, which comprises a scattered pattern of lower density settlement areas, urban concentrations around transport hubs, together with large green open spaces, such as urban woodlands, farmland, golf courses and nature reserves;

2 Urban periphery: a zone surrounding the main built-up areas, with a lower population density, but belonging to the Functional Urban Area; this may include smaller settlements, industrial areas and other urban land uses within a matrix of functional agriculture.

The suburban areas in this classification are part of the urban, built-up area. Suburban areas are generally lower density contiguous built-up areas, which are attached to inner urban areas, and where houses are typically not more than $200 \mathrm{~m}$ apart, with local shops and services, parks and gardens (Figure 4.1). 


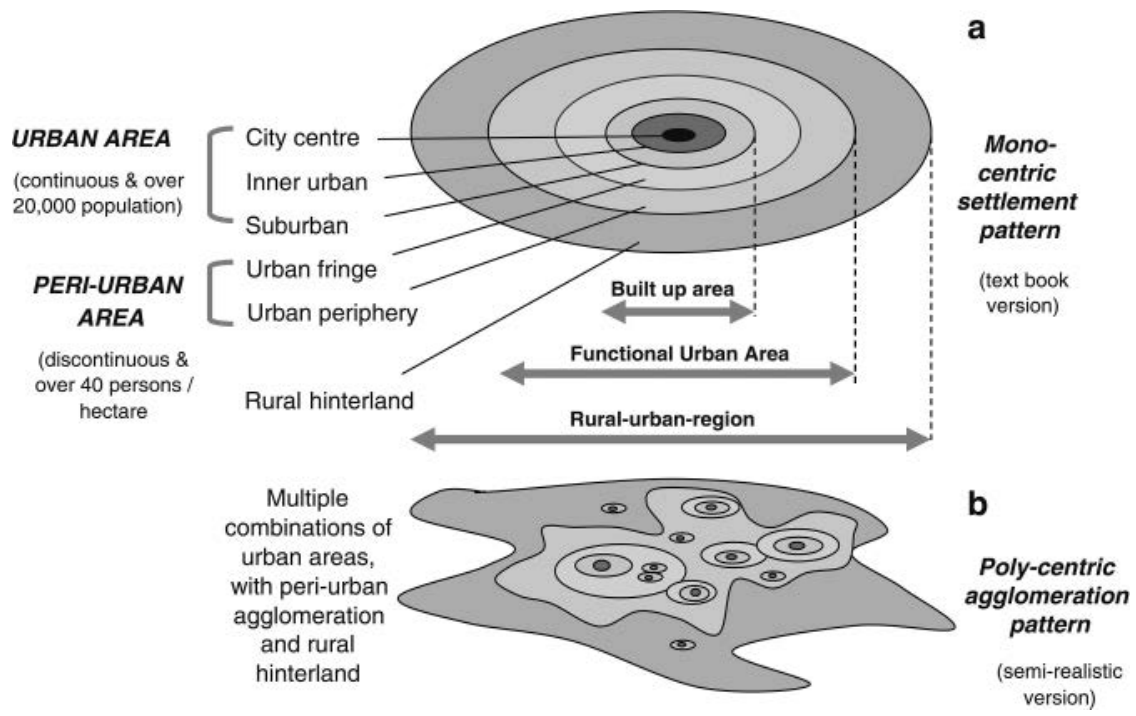

Figure 4.1 The peri-urban area as a part of the rural-urban region.

Source: Ravetz, Fertner and Nielsen 2013, 18. Reprinted by permission from Springer Nature: The Dynamics of Peri-Urbanization by Joe Ravetz, Christian Fertner, Thomas Sick (C) 2013.

\section{Changing urban systems}

The brief review of European peri-urban development suggests that dwelling dynamics are proceeding in parallel, mutually enforcing each other, but leading to contradictory outcomes. Spatial relations increasingly do not follow a conventional centre-periphery model (as, by the way, they never fully have in the past). In the contemporary globalised world, locations are linked to each other in ways that are territorially contiguous, by the everyday movement of people and goods; at the same time, places are linked to others elsewhere in spatially non-contiguous ways through virtual mobility and long-distance travel. As Manuel Castells argued, the logic of the "space of flows" is dominant in contemporary life and is associated with political and economic power (Castells 1999).

Additionally, the dominance of some urban centres in Europe has led to substantial negative agglomeration effects that fostered new town development across Europe. Such developments have resulted in metropolitan regions being more polycentric with new towns becoming hubs of employment themselves. For transport, this has resulted in the need for networks that allow tangential connectivity avoiding the central city.

Ravetz, Fertner and Nielsen (2013, 21-26) analysed different local, regional and global factors and causes that have impacts on Europe's spatial 
system. They identified three different types of urban growth and dynamics that cause the city to grow beyond its boundaries:

- Urban expansion (Figure 4.2): this is foremost a result of population and economic growth, causing a higher demand for housing and commercial areas. Transport accessibility to employment and services, as well as the attractiveness of the environment and land values then determine the new locations for housing. Physical and political constraints also play a role. Furthermore, housing demand is affected by a decrease in average household size, but also a higher demand for residential space in general. Economic and employment growth and changing employment patterns further drive urban expansion by an increase in the building stock and land-use conversion. More in the United States than in Europe, urban expansion has been driven by dependency on the automobile, creating built-up landscapes centred around cars.

- Regional agglomeration and urban-rural linkages (Figure 4.3): dynamics on an inter-urban and regional scale are constantly reshaping spatial relationships, resulting in inter-urban or regional agglomerations. Single cities are replaced by regional urban systems of inter-connected and polycentric types of settlement. Processes that occur in rural areas, such as economic restructuring, land market changes and agricultural modernisation, can also support agglomeration dynamics.

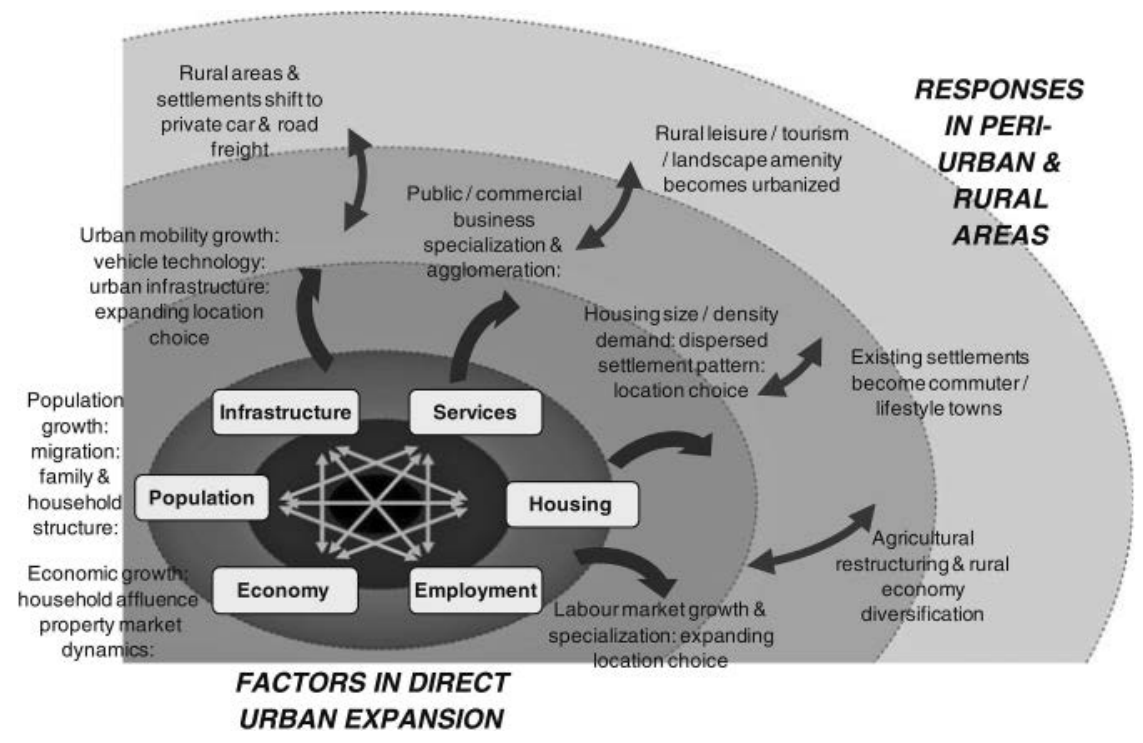

Figure 4.2 Processes of urban expansion.

Source: Ravetz, Fertner and Nielsen 2013, 22. Reprinted by permission from Springer Nature: The Dynamics of Peri-Urbanization by Joe Ravetz, Christian Fertner, Thomas Sick (C 2013. 


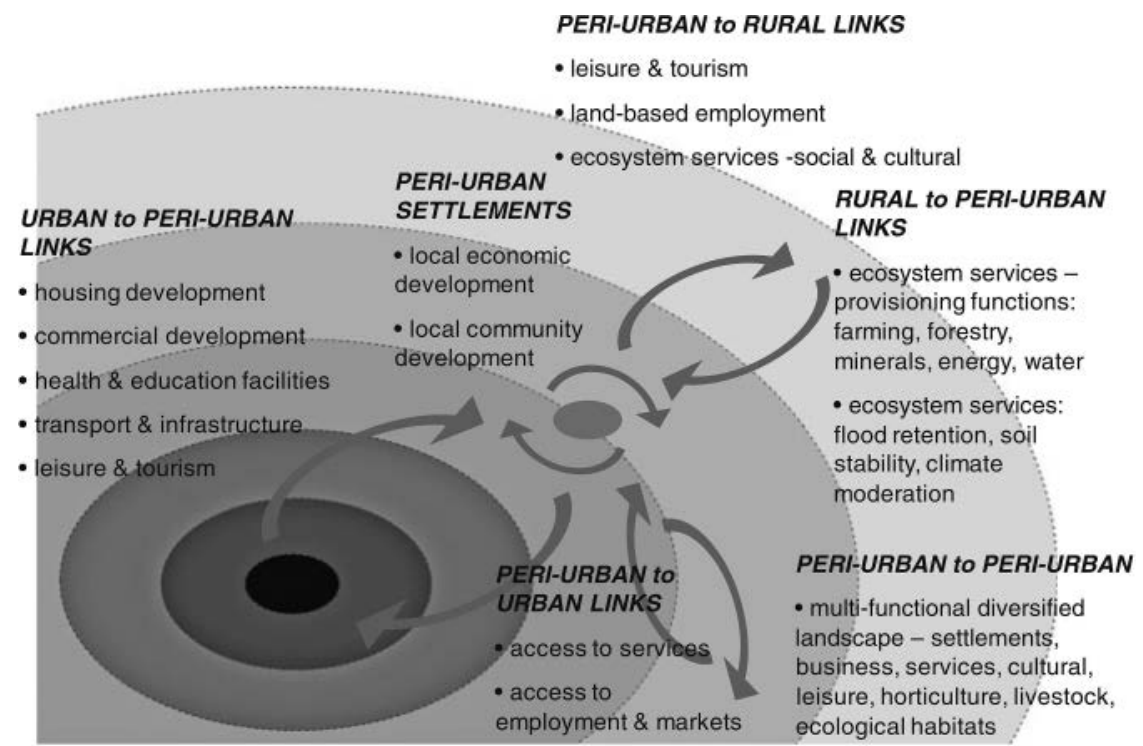

Figure 4.3 Agglomeration development and rural-urban linkages.

Source: Ravetz, Fertner and Nielsen 2013, 24. Reprinted by permission from Springer Nature: The Dynamics of Peri-Urbanization by Joe Ravetz, Christian Fertner, Thomas Sick (C 2013.

- Global-local restructuration (Figure 4.4): the main dynamic driving this process is globalisation. Globalisation has multiple effects, such as economic effects on business structures and finance; it also has political effects on the urban systems and hierarchies of nation states and $\mathrm{Eu}-$ rope as a whole and, finally, cultural effects through the media and information and communications technology (ICT) can also be observed. All these processes shape urban dynamics - growth as well as decline in combination with the aforementioned forces. Associated processes, such as privatisation and franchising, have far-reaching impacts on governance and public services. New forms of consumption, leisure and tourism have reshaped spaces far beyond traditional urban areas. In contrast to globalisation, there are also localisation processes, resulting in new cultural identities, new forms of enterprises and diverse use of spaces.

\section{Spatial categories and their challenges}

As outlined above, the challenges that individuals encounter while being mobile are directly linked to the characteristics of the space in which they move. Furthermore, social disadvantages affect people differently in rural, peri-urban and urban areas. While the rural-urban differentiation seems 


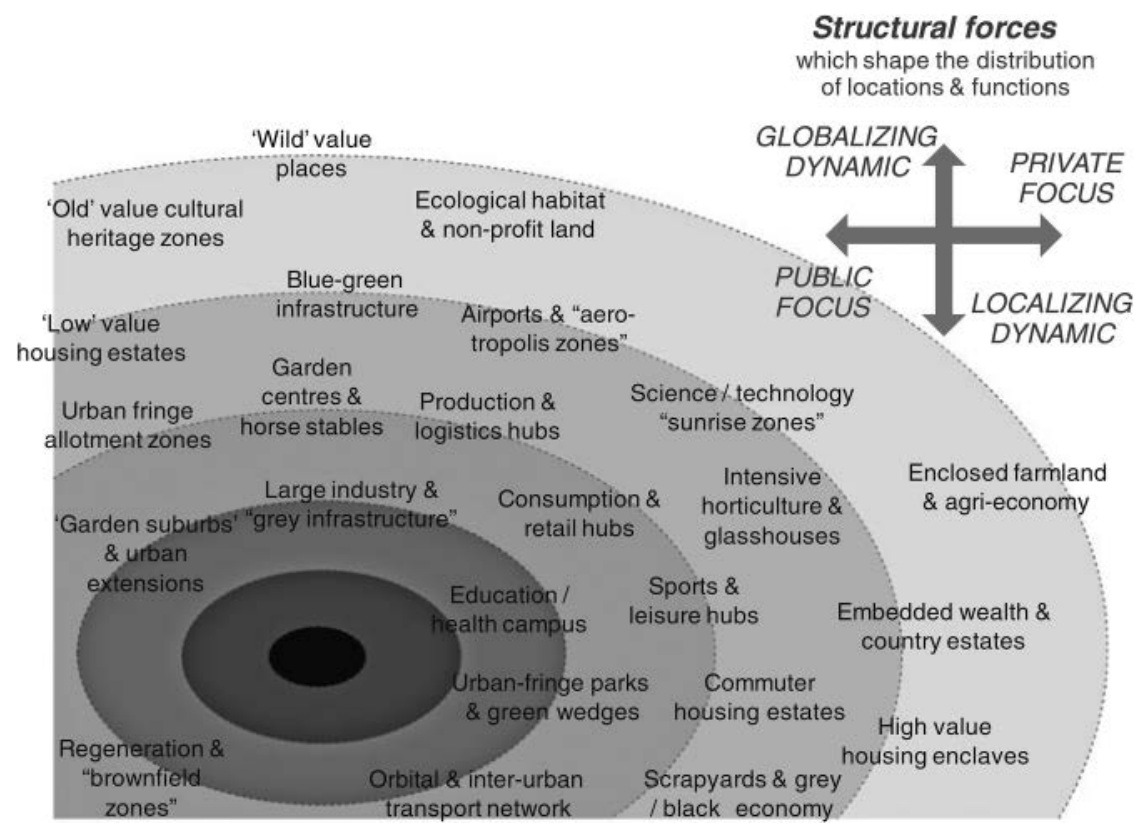

Figure 4.4 Global-local restructuration.

Source: Ravetz, Fertner and Nielsen 2013, 26. Reprinted by permission from Springer Nature: The Dynamics of Peri-Urbanization by Joe Ravetz, Christian Fertner, Thomas Sick (C) 2013.

obvious at first sight, as illustrated above, it is often difficult to say where the city ends and a rural area begins. In many regards, today peri-urban and rural areas exhibit the same characteristics as urban areas. Therefore, rather than separating spaces, it is conceptually helpful to understand how different urban and rural spaces are always linked to each other by movements of any kind.

Economic characteristics of a given area are often used to define the urban and the rural. From this perspective, the urban is usually identified by its economic activities being mostly non-agricultural. Moreover, the diversity of economic activities in services and production is considered in urban areas, while economic activities in rural areas are usually less heterogeneous. Another way of separating the urban and the rural is to identify areas that are related to urban cores in a functional way, which are often economic links. A functional definition that is related to a city's economy is the territory delimited by the commuting interrelations around a core city (Frey and Zimmer 2000).

Definitions of metropolitan areas take a similar approach by identifying a contiguous area that is under the primary influence of an urban core, which encompasses more and less dense areas. Lastly, urban areas can be 
differentiated from rural ones by their degree of "urbanism", meaning the social characteristics of a settlement. In this vein, it is usually argued that urban lifestyles differ from rural ones and so do people's worldviews, values and behaviours (Frey and Zimmer 2000).

Such categorisations highlight that the urban and the rural exist as a continuum. For example, considering the territorial limits of functional links to and from a city, it must indeed be recognised that for a long time agricultural production in rural areas has served to sustain the increasing population living in cities. Seen from that functional perspective, most agricultural space is an extended urban space. Furthermore, in industrialised countries, urban lifestyles have become prevalent in densely as well as sparsely populated areas, not least due to the opportunities of ICT. On the other hand, in the Global South, many rural migrants living in cities maintain traditional rural lifestyles. Consequently, several academics have argued that there is no longer anything beyond the urban, declaring that the contemporary world is characterised by "planetary urbanism" (Brenner and Schmid 2015).

European countries have historically used different methodologies to classify their spaces and settlements. This has the effect that a settlement which is called a city in one country would be regarded as a village in another. For example, in Denmark, a settlement is called a city when the population is above 200 inhabitants in a contiguous built-up area with distances between houses of not more than 200 metres (Statistics Denmark 2014). In Germany, the urban category is defined by population size and its position in the hierarchy of supply centres. The smallest urban settlement starts with a population of 5,000, given the fact that this settlement is a basic supply centre to the region. However, where a settlement has fewer than 5,000 inhabitants but is categorised as a basic supply centre, that settlement is a "rural town" (Bundesinstitut für Bau-, Stadt- und Raumforschung 2015). These examples show that, although both countries include population size as a measure to classify settlements, they can hardly be compared based on these definitions.

\section{Urban functions and accessibility in Europe}

Accessibility is of crucial importance when analysing mobility poverty. People on low income and those experiencing social disadvantage often experience below-average accessibility. Poor accessibility leads to fewer opportunities of social interaction and fulfilment (e.g. health or educational services), with direct impact on a person's quality of life and well-being. As a result, people living in such areas often need to resort to private car use to fulfil their mobility needs. Páez et al. (2009) studied the transport accessibility limitations of three vulnerable segments - the elderly, those on low income and single parents - regarding three activities - accessing health care, food services and jobs - respectively. The study recorded low 
accessibility for the three groups, even in the case of those persons owning (or using) a car. The study makes evident that the regions where vulnerable segments live exhibit a lower density of relevant activities (compared with other areas), requiring the people living in such a region to travel for longer or preventing them from accessing such activities.

Such findings highlight the necessity to shed light on accessibility in different European regions, especially those regions that exhibit low population density and low density of opportunities that need to be accessed in everyday life. Opportunities for basic everyday needs are mostly concentrated in regional towns and cities, while locations that cater for specialised needs can be found in larger cities. There are substantial differences across Europe in terms of time needed to reach regional towns and cities, posing a disadvantage to those living in low-density, remote areas.

Figure 4.5 shows the accessibility of cities larger than 50,000 inhabitants within 60 minutes of road travel time while Figure 4.6 shows the same for 60 minutes of rail travel time. ${ }^{1}$ From most locations in Western and Central Europe, at least one regional city can be reached by road within 60 minutes; from many places, even more than ten regional cities. Accessibility by road and rail is thus highest in the centre of Europe. Highly urbanised parts of the United Kingdom, the Netherlands, Belgium and Germany (e.g. the Ruhr region) have the best accessibility by road and rail in Europe. Also, in and around cities in western and eastern France, many parts of Germany, the north of Italy and some parts of Spain, accessibility by road and rail is high.

The analysis of accessibility by road and rail highlights those regions in Europe that do not have access to urban functions in reasonable time. These are regions like Mecklenburg-Western Pomerania (Germany), many parts of France and Spain and areas in Poland and the Czech Republic. For rail, the extent of these areas is even bigger in almost all countries (Spiekermann et al. 2013, 113-116).

To understand how regional accessibility and mobility poverty are related to dynamics at macro level, the impact of globalisation on European regions needs to be addressed. This is also necessary because the concentration of economic activity, employment opportunities and other vital functions in larger cities is likely to continue in the future, while at the same time the disconnection of peripheral regions is continuing, reducing economic activity, employment opportunities and quality of life in these regions (Martinez-Fernandez et al. 2012).

Globalisation and the development of cities with Global City status have greatly impacted accessibility levels in Europe. Globally connected cities like London, Paris, Amsterdam and Frankfurt benefit from their welldeveloped urban transport systems, their integration into high-speed rail networks as well as their international airports allowing direct connections to other world cities. While these cities benefit from their above-average accessibility levels, smaller cities struggle to reach similar levels of global and inter-metropolitan connectivity (Spiekermann et al. 2013, 77-80). 


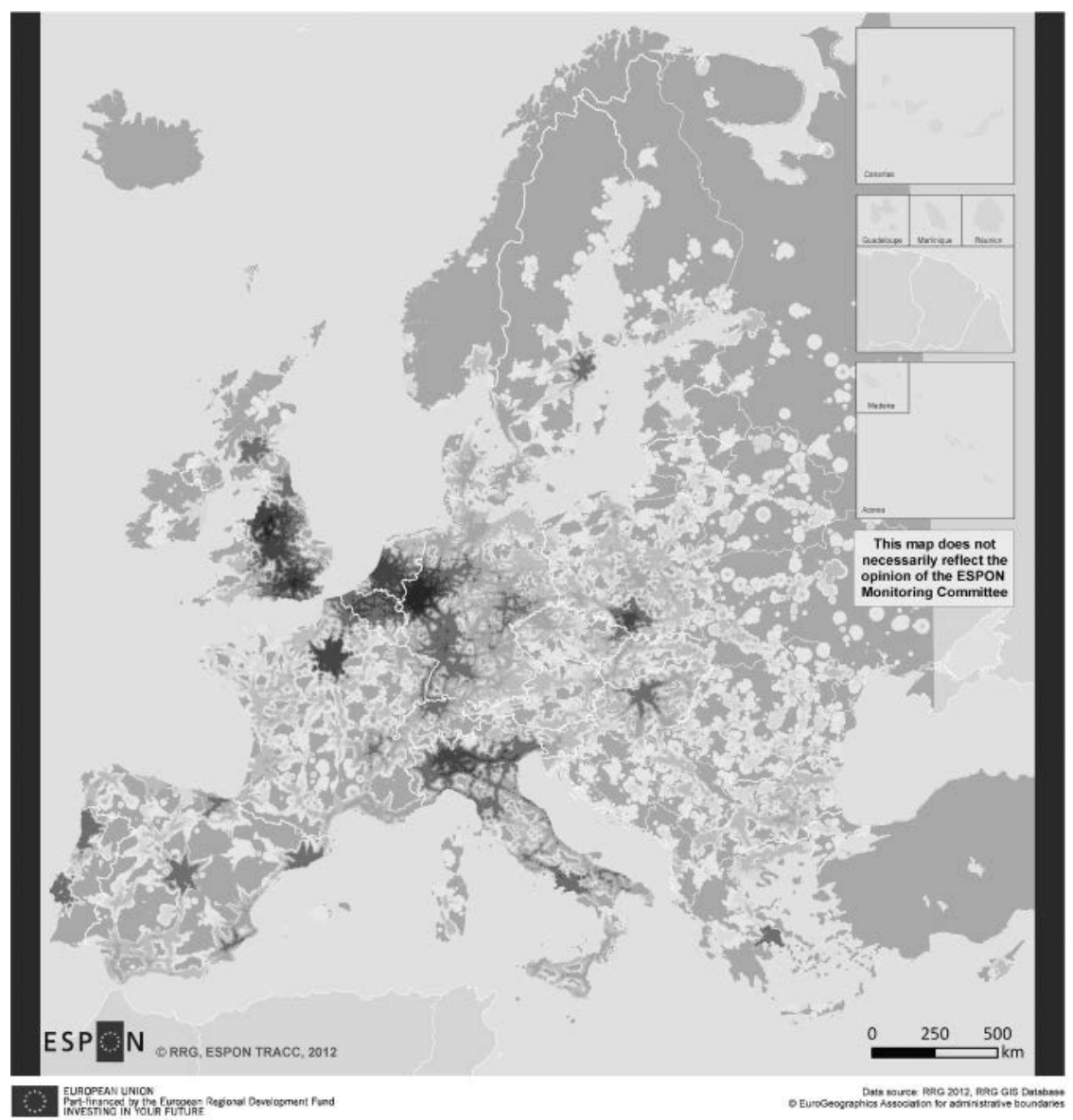

\section{Availability of urban functions (2011):}

\section{Number of cities $>\mathbf{5 0 , 0 0 0}$ inhabitants within}

60 minutes road travel time (raster level)

$\square$
$\square$
1
2
$3-5$
$5-10$
$11-25$
$26-50$
$51-76$

Figure 4.5 Accessibility of urban functions (2011): Number of cities $>50,000$ inhabitants within 60 minutes' road travel time.

Source: Spiekermann et al. 2013, 114. 


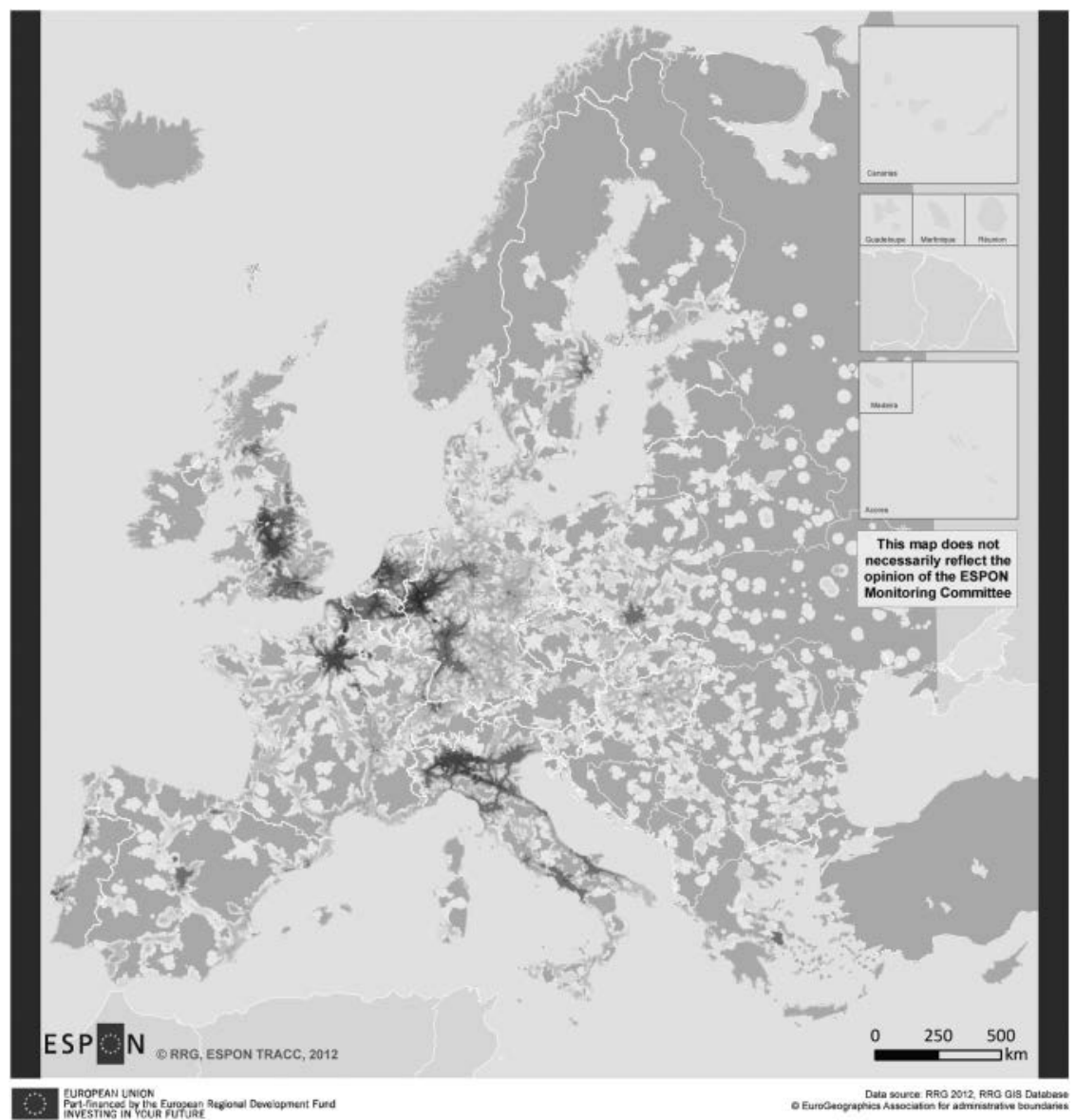

\section{Availability of urban functions (2011):}

Number of cities $>\mathbf{5 0 , 0 0 0}$ inhabitants within

60 minutes rail travel time (raster level)

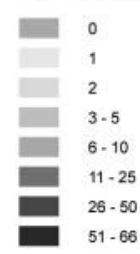

Figure 4.6 Accessibility of urban functions (2011): Number of cities $>50,000$ inhabitants within 60 minutes' rail travel time.

Source: Spiekermann et al. 2013, 115. 
As an example of global accessibility, Figure 4.7 highlights travel times to New York from Europe, providing a good impression of how different accessibility levels are in different European regions.

These figures show how Europe's spatial and transport systems have developed around an agglomeration of large cities in central Western Europe

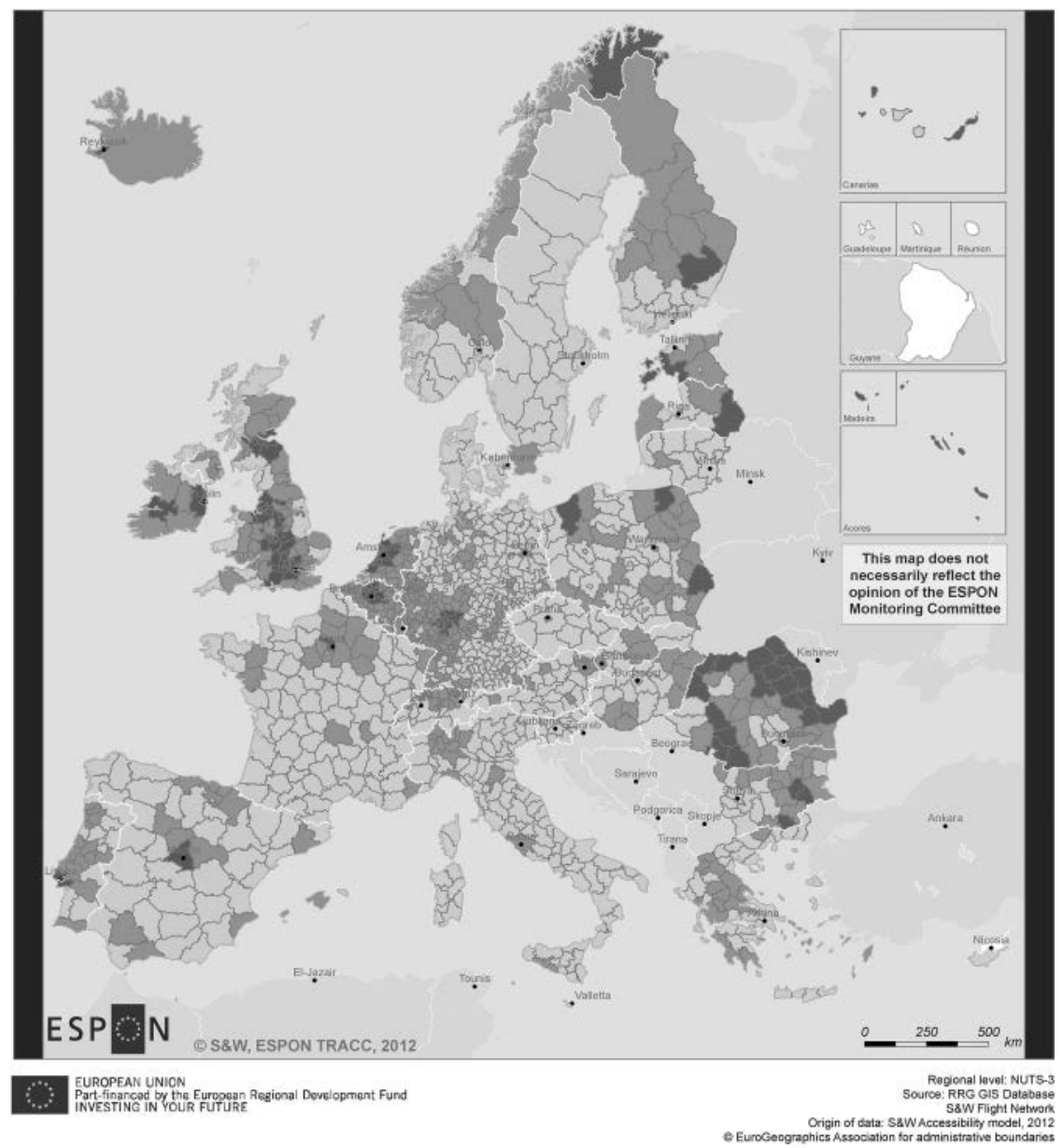

Travel Time to New York, intermodal (minutes)



Figure 4.7 Global accessibility of European Regions with the example of travel times to New York, intermodal (minutes).

Source: Spiekermann et al. 2013, 78. 
and, in contrast, how development in peripheral regions of Europe has been at a comparatively lower level. However, Europe's spatial development cannot simply be described as a model of centres and peripheries. Additionally, with the eastern and southern extensions of the European Union, the historical spatial hierarchy is going to be challenged in the future.

\section{Spatial effects on everyday mobility: the burden of commuting}

Commuting between one's home and place of work is one of the primary effects of the changing spatial system of Europe. As suburban sprawl is increasing, commutes are becoming longer.

An individual's commuting behaviour is dependent on both the situation of the housing market and the labour market. Individuals have to optimise their personal situation in the context of these two markets. This could mean that, in certain situations, either a change of job or residence is required to cater to someone's personal situation. However, with both housing and employment situations being tight, the distances of commuting and time required for commuting can amount to a substantial burden for individuals (Lorenz 2018). Such situations are partially counteracted by low-cost, frequent and quick long-distance mobility options, increasing the number of long-distance commuters in Europe (Lyons and Chatterjee 2008; Sandow 2019; Viry 2015).

Commuting can be defined in different ways. Usually, a commuter is considered to be a person crossing a municipal border on the way from home to work. Actual numbers on commuting in Europe are provided by the European Statistical Office (Eurostat), which analyses commuting patterns at regional (NUTS 2) level. In 2015, the total number of employed persons in the European Union (28) was 220.7 million. The overall majority $(91.9 \%)$ of people employed lived in the same region (defined here at NUTS level 2) as where they worked (including those working from home). This means that $8.1 \%$ of the workforce commuted to work in a different region. In Belgium, the highest rate of commuting was recorded in 2015. More than one in five $(21.9 \%)$ persons commuted to work in a different region (NUTS level 2). Also, in the United Kingdom, the Netherlands, Austria and Slovakia, high shares of commuting to a different region can be observed. ${ }^{2}$

Commuting substantially shapes the everyday life of millions of Europeans residents. Not only do European commuters spend a lot of time in cars and trains; commuting is also considered to be a burden and diminishes subjective well-being (Stutzer and Frey 2008; Wurhofer et al. 2015). However, it has also been highlighted that commuting by car in particular is perceived as desirable due to the freedom that a car provides and the potential to enable someone to break free from day-to-day responsibilities (Boyle 2016). Cycling commuters who report dangerous experiences during their regular work commute also highlight their well-being, enjoyment and 
happiness of doing physical exercise and the ability to wind down after work (Guell et al. 2012).

The analysis of commuting times in Europe illuminates the time-related burden that many Europeans face. With longer commutes, the relationship between commuting and well-being is a prime concern.

A 2015 survey asked for the commuting times of citizens in European member states. The mean commuting time of survey respondents was highest in the UK and Sweden with more than 50 minutes for travelling from home to work and back. The lowest mean commuting times were reported from Italy, Portugal and Cyprus (less than 30 minutes) (Eurostat 2015).

Between 2005 and 2015, the overall mean commuting time in the EU decreased slightly. This is due to contrasting developments in commuting in the member states: while in most of the western and northern member states, mean commuting times increased, in some countries by more than five minutes; commuting times in most eastern and southern member states decreased (see Figure 4.8). In some member states, like Slovakia, Cyprus, Poland and Romania, commuting times decreased by more than 15 minutes (Eurostat 2015).

According to this survey, almost $25 \%$ of survey respondents travelled more than one hour from home to work and back (see Figure 4.9). About $2 \%$ travelled more than two hours from home to work and back. The highest share of those commuting more than one hour was found in the United Kingdom (35\%), including the highest share among member countries of those who travelled more than two hours (5\%). After the United Kingdom, similarly high shares of survey respondents reported commuting times

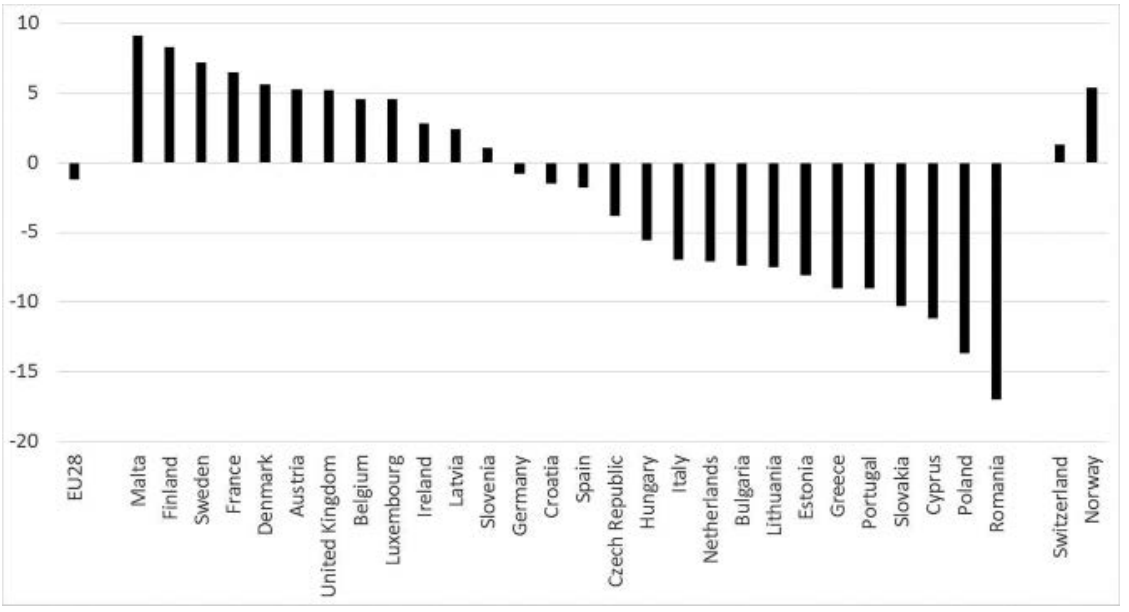

Figure 4.8 Change in mean commuting time 2005-2015 (in minutes).

Source: Authors, based on Eurostat 2015. 


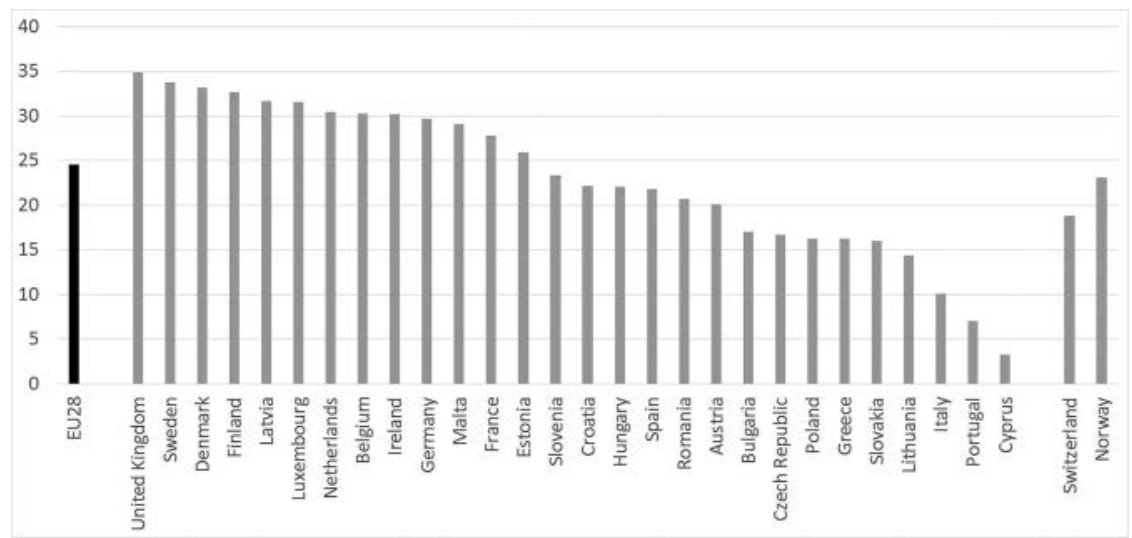

Figure 4.9 Share of employed population with mean commuting time of more than one hour.

Source: Authors, based on Eurostat 2015.

longer than one hour. The lowest shares were observed in Italy, Portugal and Cyprus (10\% and lower) (Eurostat 2015).

However, the burden of commuting is not only about the time spent in a mode of transportation per se. Anger and frustration during commuting are a common experience for every commuter. Frustration, anger and stress during a car commute are experienced when unexpected congestion occurs, leading to fear about job-related consequences. Being stuck in traffic congestion is often perceived as a waste of time and a loss of spare time. Also, being stuck in traffic is associated with a loss of control (Guell et al. 2012; Wurhofer et al. 2015). Similarly, longer commuting distances are associated with lower satisfaction with family life and leisure time (Lorenz 2018).

The burden of commuting can become a severe disadvantage when an individual also experiences a disadvantage on the housing and labour market. In the context of mobility poverty, this means that instead of experiencing a low level of mobility, the experience of travelling due to compulsion causes a significant burden. Especially for those with low financial means and limited social and professional networks, any adjustment to optimise the balance between the housing market and labour market is limited. This can lead to substantial distances and time spent travelling that is not compensated by a higher income or a lower rent. Also, people who become employed again after a period of unemployment may start with a less attractive job that includes long journeys to work (Stutzer and Frey 2008).

Furthermore, a study in the United States showed that increased commuting reduces political participation, a phenomenon that can be observed particularly among poor households. Newman, Johnson and Lown $(2014,29)$ state: "While higher income individuals are not immune from having to 
commute, $[. .$.$] the negative effect of commuting with respect to political in-$ terest and participation is entirely concentrated among the lower working class".

There are also differences when taking gender into perspective. A study from the United Kingdom highlights that commuting has a higher negative effect on the well-being of women, due to their larger responsibility for dayto-day household tasks, including childcare (Roberts, Hodgson, and Dolan 2011). Although the share of highly educated women in long-distance commuting is larger than male commuters, the majority of women long-distance commuters are low-income earners. This means that men benefit financially more than women from long-distance commuting (Sandow 2019; Sandow and Westin 2010).

Higher commuting burdens are also reported for immigrants and ethnic minorities. The spatial mismatch of housing and job opportunities and its adverse effects (e.g. in the form of a commuting burden) on African American communities in racially segregated cities in the United States has controversially been discussed since the 1960s (Gobillon and Selod 2013). A study from Madrid in Spain showed that immigrants face higher commuting times than the domestic population. This difference is partially a result of residential segregation in certain parts of the city and difficulties in employment accessibility (Blázquez, Llano, and Moral 2010).

\section{Notes}

1 Cities with at least 50,000 inhabitants are selected as destinations, assuming that only cities of that minimum size provide a full range of public and private services and functions.

2 These figures are also the effect of the different sizes of the NUTS 2 regions. Especially for Belgium, the Netherlands and the UK, as these countries are densely populated, and the NUTS 2 regions are small in area size. This is confirmed by the observation that in Greece, Spain, Portugal and Romania, commuting across regions is relatively low because the NUTS 2 regions in these countries are very large (Eurostat 2016).

\section{References}

Allen, Adriana. 2010. "Neither rural nor urban: service delivery options that work for the peri-urban poor." In Peri-urban Water and Sanitation Services: Policy, Planning and Method, edited by Mathew Kurian and Patricia McCarney, 27-61. Dordrecht: Springer, Springer Science \& Business Media.

Blázquez, Maite, Carlos Llano, and Julian Moral. 2010. "Commuting times: Is there any penalty for immigrants?” In Urban Studies 47 (8): 1663-1686. https://doi. org/10.1177/0042098009356127.

Boyle, Patrick. 2016. "Routine journeys, complex networks: media-centrism, the dispositif of road safety, and practices of commuting by car in everyday Ireland." Doctoral Dissertation, Maynooth University. https://pdfs.semanticscholar.org/ a569/b7fc7a2f32e0617736bad14d4e7f5cd61bb1.pdf. Accessed 24 March 2020. 
Brenner, Neil, and Christian Schmid. 2015. "Towards a new epistemology of the urban?" In City 19 (2-3): 151-182. https://doi.org/10.1080/13604813.2015.101471.

Bundesinstitut für Bau-, Stadt- und Raumforschung. 2015. "BBSR Homepage Stadt- und Gemeindetyp." https://www.bbsr.bund.de/BBSR/DE/Raumbeobach tung/Raumabgrenzungen/StadtGemeindetyp/StadtGemeindetyp_node.html. Accessed 25 May 2018.

Castells, Manuel. 1999. "Grassrooting the space of flows." In Urban Geography 20 (4): 294-302. https://doi.org/10.2747/0272-3638.20.4.294.

Council of Europe. 2007. Spatial Development Glossary: European Conference of Ministers Responsible for Regional/Spatial Planning (Cemat). Bilingual. Territory and Landscape Series v.2. Strasbourg: Council of Europe. https://rm.coe. int/CoERMPublicCommonSearchServices/DisplayDCTMContent?documentId= 09000016804895 e5. Accessed 7 June 2018.

Douglas, Ian. 2012. "Peri-urban ecosystems and societies: Transitional zones and contrasting values." In The peri-urban Interface: Approaches to Sustainable Natural and Human Resource Use, edited by Duncan McGregor and David Simon, 41-52. Abingdon: Routledge.

Errington, Andrew. 1994. "The peri-urban fringe: Europe's forgotten rural areas.” In Journal of Rural Studies 10 (4): 367-375. https://doi.org/10.1016/0743-0167 (94)90046-9.

Eurostat. 2015. "How many minutes per day do you usually spend travelling from home to work and back?" https://c-adm.eige.europa.eu/data/view?code=ta_time use_wktime_comm_ewcs_commutetime_mean. Accessed 21 April 2020.

Eurostat. 2016. "Statistics on commuting patterns at regional level." https://ec.europa. eu/eurostat/statistics-explained/pdfscache/50943.pdf. Accessed 24 June 2020.

Forum Mobile Lives. 2013. "Rehabilitating the peri-urban: How to live and move sustainably in these areas?" http://en.forumviesmobiles.org/publication/livresforum/2013/09/25/rehabilitating-peri-urban-1276. Accessed 10 May 2018.

Frey, William H., and Zachary Zimmer. 2000. "Defining the city." In Handbook of Urban Studies edited by Ronan Paddison, 14-35. London: Sage Publications.

Gant, Robert L., Guy M. Robinson, and Shahab Fazal. 2011. "Land-use change in the 'edgelands': Policies and pressures in London's rural-urban fringe." In Land Use Policy 28 (1): 266-679. https://doi.org/10.1016/j.landusepol.2010.06.007.

Gobillon, Laurent, and Harris Selod. 2013. "Spatial mismatch, poverty, and vulnerable populations." In Handbook of Regional Science, edited by M. M. Fischer and Peter Nijkamp. Berlin, Heidelberg: Springer.

Guell, Cornelia, Jenna Rachel Panter, Natalia R. Jones, and David B. Ogilvie. 2012. "Towards a differentiated understanding of active travel behaviour: using social theory to explore everyday commuting.” In Social Science \& Medicine 75 (1): 233239. https://doi.org/10.1016/j.socscimed.2012.01.038.

Hall, Peter. 2003. "A European perspective on the spatial links between land use, development and transport." In Transport and Urban Development, edited by David Banister, 75-98. Abingdon: Routledge.

Hart, Tom. 2000. "Transport and the city." In Handbook of Urban Studies edited by Ronan Paddison, 102-123. London: Sage Publications.

Lorenz, Olga. 2018. "Does commuting matter to subjective well-being?" In Journal of Transport Geography 66: 180-199. https://doi.org/10.1016/j.jtrangeo. 2017.11.019. 
Lyons, Glenn, and Kiron Chatterjee. 2008. "A human perspective on the daily commute: Costs, benefits and trade-offs.” In Transport Reviews 28 (2): 181-198. https:// doi.org/10.1080/01441640701559484.

Martinez-Fernandez, Cristina, Ivonne Audirac, Sylvie Fol, and Emmanuele Cunningham-Sabot. 2012. "Shrinking cities: Urban challenges of globalization." In International Journal of Urban and Regional Research 36 (2): 213-225. https:// doi.org/10.1111/j.1468-2427.2011.01092.x.

Nelson, Arthur C., and Thomas W. Sanchez. 1999. "Debunking the exurban myth: A comparison of suburban households." In Housing Policy Debate 10 (3): 689-709.

Newman, Benjamin J., Joshua Johnson, and Patrick L. Lown. 2014. "The "daily grind" work, commuting, and their impact on political participation." In American Politics Research 42 (1): 141-170. https://doi.org/10.1177/1532673X13498265.

Páez, Antonio, Ruben Mercado, Steven Farber, Catherine Morency, and Polytechnique Montréal. 2009. Mobility and Social Exclusion in Canadian Communities: An Empirical Investigation of Opportunity Access and Deprivation. Quebec: Policy Research Directorate, Strategic Policy and Research, Government of Canada.

Ravetz, Joe, Christian Fertner, and Thomas S. Nielsen. 2013. "The dynamics of peri-urbanization." In Peri-urban Futures: Scenarios and Models for Land Use Change in Europe, edited by Kjell Nilsson, Stephan Pauleit, Simon Bell, Carmen Aalbers, and Thomas A. S. Nielsen, 13-44. Berlin and Heidelberg: Springer Verlag.

Roberts, Jennifer, Robert Hodgson, and Paul Dolan. 2011. “"It's driving her mad": Gender differences in the effects of commuting on psychological health." In Journal of Health Economics 30 (5): 1064-1076. https://doi.org/10.1016/j. jhealeco.2011.07.006.

Sandow, Erika. 2019. "Til work do us part: The social fallacy of long-distance commuting." In Integrating Gender into Transport Planning: From One to Many Tracks, edited by Christina Lindkvist Scholten and Tanja Joelsson, 121-144. London: Palgrave Macmillan.

Sandow, Erika, and Kerstin Westin. 2010. "The persevering commuter - Duration of long-distance commuting." In Transportation Research Part A: Policy and Practice 44 (6): 433-445. https://doi.org/10.1016/j.tra.2010.03.017.

Spiekermann, Klaus, Michael Wegener, Viktor Květoň, Miroslav Marada, Carsten Schürmann, Oriol Biosca, Andreu Ulied Segui, Harri Antikainen, Ossi Kotavaara, Jarmo Rusanen, Dorota Bielańska, Davide Fiorello, Tomasz Komornicki, Piotr Rosik, and Marcin Stepniak. 2013. "TRACC transport accessibility at regional/ local scale and patterns in Europe." https:/www.espon.eu/sites/default/files/ attachments/TRACC_FR_Volume2_ScientificReport.pdf. Accessed 25 March 2020.

Statistics Denmark. 2014. "Documentation of statistics for urban areas 2014." http:// www.dst.dk/Site/Dst/SingleFiles/kvaldeklbilag.aspx?filename=adcefe43-2802462f-9ba6-38d790b6c6dcUrban_Areas_2014. Accessed 25 May 2018.

Stutzer, Alois, and Bruno S. Frey. 2008. "Stress that doesn't pay: The commuting paradox." In Scandinavian Journal of Economics 110 (2): 339-366. https://doi. org/10.1111/j.1467-9442.2008.00542.x.

Wurhofer, Daniela, Alina Krischkowsky, Marianna Obrist, Evangelo Karapanos, Evangelos Niforatos, and Manfred Tscheligi. 2015. "Everyday commuting: prediction, actual experience and recall of anger and frustration in the car." In 


\section{Tobias Kuttler}

Proceedings of the 7th International Conference on Automotive User Interfaces and Interactive Vehicular Applications, 233-240. https:/doi.org/10.1145/2799250.27 99251.

Zasada, Ingo, Susana Alves, Felix Claus Müller, Annette Piorr, Regine Berges, and Simon Bell. 2010. "International retirement migration in the Alicante region, Spain: Process, spatial pattern and environmental impacts." In Journal of Environmental Planning and Management 53 (1): 125-141. https://doi.org/10. 1080/09640560903399905.

Zasada, Ingo, Christian Fertner, Annette Piorr, and Thomas Alexander Sick Nielsen. 2011. "Peri-urbanisation and multifunctional adaptation of agriculture around Copenhagen." In Geografisk Tidsskrift-Danish Journal of Geography 111 (1): 59-72. https://doi.org/10.1080/00167223.2011.10669522. 